\title{
Factors associated with different smoking statuses among Malaysian adolescent smokers: a cross-sectional study
}

\author{
A. H. Nur Atikah', Lei Hum Wee ${ }^{1 *}$, M. S. Nur Zakiah', Caryn Mei Hsien Chan, N. M. Mohamed Haniki², \\ J. S. Swinderjit ${ }^{3}$ and Ching Sin Siau ${ }^{1,4}$
}

\begin{abstract}
Background: This study focused on the associations between socioeconomic status (SES) and adolescent smoking among secondary school students (13 to 17 years) in the Federal Territory of Kuala Lumpur, Malaysia. Our objective was to evaluate the relationships between adolescent demographics, socioeconomic status and smoking status.

Methods: The survey data were based on baseline findings from a cross-sectional study ( $N=422$ adolescents). Chisquare test was used to assess the relationship between demographic characteristics, socioeconomic status (household monthly income and daily allowance) and adolescent smoking status. Exhaled carbon monoxide (CO) reading and the Hooked on Nicotine Checklist (HONC) were used to evaluate adolescent smoking status. A Multivariate Multinomial Logistic Regression (MMLR) was employed to test selected demographic and socioeconomic predictors of smoking status.

Results: Of the 422 adolescents ( $M$ age $=15.58, S D=1.24$ ), more than half of the participants initiated smoking between 13 to 17 years old (59.0\%). A total of 308 (73.0\%) were electronic cigarette users, with more than 50\% comprising of single users. The mean CO reading was $2.14 \mathrm{ppm}$ with $78.0 \%$ of adolescents scoring more than 0 on the Hooked on Nicotine Checklist (HONC). Males and participants aged 15 and 16 years were at increased risks of sole CC smoking. Meanwhile, males, those who are not hooked on smoking and with a non-smoker CO reading were at increased risks of sole EC smoking. Finally, Bumiputeras were at less risk of EC smoking.

Conclusions: Demographic variables such as age, gender and ethnicity predicted smoking status predicted smoking risk, but not socioeconomic factors. The findings allow policy makers to target specific high-risk demographic groups when designing smoking cessation programs for adolescents.
\end{abstract}

Keywords: Socioeconomic, Smoking status, Preference, Adolescents, Malaysia

\section{Background}

Adolescence marks a critical growth period, with many lifetime health behaviors formed during this time. This is a crucial stage for the development of health behaviors such as smoking and the habits that develop during this stage of life are often carried over into adulthood [1-3]. Rapid physical, social, emotional and cognitive development during this period of development is typically characterized by curiosity and smoking experimentation/

\footnotetext{
* Correspondence: weeleihum@ukm.edu.my

${ }^{1}$ Health Education Program, Community Health Centre, Faculty of Health Sciences, The National University of Malaysia (UKM), Kuala Lumpur, Malaysia Full list of author information is available at the end of the article
}

initiation [3]. Thus, targeting the prevention of smoking at this juncture may be key to the reduction of many preventable chronic diseases in adulthood. The need and urgency of this issue takes on new meaning with the high prevalence of adolescent smoking in Malaysia, where 1 in 10 adolescents in the 13 to 17 -year-old age group are smokers [4]. Examining the sociodemographic characteristics of adolescent smoking is the key step toward its prevention.

In order to intervene with adolescent smoking, there is a need to grasp the rapidly changing landscape of adolescent tobacco use, which is marked by recent decreases in combustible cigarette smoking and overall increases

(c) The Author(s). 2019 Open Access This article is distributed under the terms of the Creative Commons Attribution 4.0 International License (http://creativecommons.org/licenses/by/4.0/), which permits unrestricted use, distribution, and reproduction in any medium, provided you give appropriate credit to the original author(s) and the source, provide a link to the Creative Commons license, and indicate if changes were made. The Creative Commons Public Domain Dedication waiver (http://creativecommons.org/publicdomain/zero/1.0/) applies to the data made available in this article, unless otherwise stated. 
in the use of electronic cigarettes (EC) and other nicotine delivery systems such as shisha [5-9]. A study on EC use among Malaysian adolescents, indicated that $40.9 \%$ used EC once a day and the prevalence of current dual users was $5.2 \%$ or 0.17 million [10]. In the United States, the increase in polytobacco use was significant only for those below 25 years old [3]. There is evidence that EC is increasingly becoming a gateway for non-users to become cigarette smokers among adolescents [2]. Among polytobacco users, waterpipe tobacco such as shisha is becoming more prevalent [5, 7-9]. EC and Shisha use are perceived to be trendy, less harmful than cigarette smoking and is socially acceptable among peers $[11,12]$. The popularity of EC and other new tobacco products have led to increasing numbers of dual and polytobacco users (more than two tobacco products used concurrently) [13].

A few factors have been linked to higher risks of sole, dual and polytobacco use, notably demographic variables such as gender, age, ethnicity, income and smoking intensity. Worldwide, males are more at risk of smoking behavior compared to females [14-17], even though the gap is smaller in European countries compared to Asia [18]. This phenomenon has been attributed to social stereotypes of smoking as being "unfeminine" [19]. Early adolescents are at less risk of smoking compared to older adolescents [2, 20-22]. Meanwhile, the Malay Bumiputera ethnicity has a higher prevalence of smoking compared to other ethnicities [17, 23].

Past studies indicated that lower socioeconomic status (SES) was an important predictor of tobacco smoking among adolescents [1, 24-26]. Green and colleagues' [1] research revealed that adolescents from low SES households reported increased initiation and escalation of tobacco use. Smokers from the lower SES group also reported a lower intention to quit [27]. Recent research [28-30] posited that the socialization of adolescents from lower income families of origin, such as the modelling or unhealthy lifestyles and health beliefs, could be transmitted intergenerationally to influence the adolescent's smoking behavior. On the other hand, the uptake of EC and polytobacco use were highly associated with higher familial and personal income among smokers [22, 31].

The objective of this study was therefore to identify the demographic and socioeconomic characteristics of adolescent smokers and its relationships with adolescent smoking status.

\section{Methods}

\section{Study design}

This is a cross-sectional school-based study, conducted from January to February 2018.

\section{Participants and sampling}

Two levels of sampling were employed: schools were selected using stratified random sampling, whereas the students were purposively selected and invited. A total of six out of $89 \mathrm{sec}-$ ondary schools were selected randomly from all zones in the Federal Territory of Kuala Lumpur, with the ratio of two schools for each of the three zones (Bangsar/Pudu, Sentul and Keramat). Student participants were purposively recruited. A total of 422 students who either smoked conventional cigarettes (CC), electronic cigarettes (EC) and/or shisha for the last 30 days, either self-declared or identified by their discipline teachers to participate in the study. Written consent was obtained from participants, parents and schools.

\section{Instruments}

A stop smoking questionnaire which went through a backward-forward translation from English to Bahasa Malaysia was used for data collection. The questionnaire consisted of demographic characteristics (class, age, year of birth, gender, and race), participants' daily allowance, monthly household income of parents, measurements related to CC/EC status (Have you ever used a CC/EC, even one or two puffs; age of CC/EC initiation; CC brand and preferable flavor of EC). The smoking status of adolescents was determined based on the question, "Have you ever used: 1. Conventional cigarettes only, 2. Electronic cigarettes only, and 3. A combination of conventional and electronic cigarettes?" The adolescents who answered using only conventional cigarettes were categorized as sole CC users, only electronic cigarettes as sole EC users, and CC and EC use as dual users [32]. The Hooked on Nicotine Checklist (HONC) [33, 34] questionnaire used to determine the onset and strength of tobacco dependence of $\mathrm{CC}$ and $\mathrm{EC}$ by adding the EC element to the original version. A HONC score of $\geq 1$ indicates a participant is hooked to smoking. The Malay translated HONC reported a Cronbach's $\alpha=0.924$.

Exhaled CO level was used to objectively identify the participants' smoking status. Those with $\mathrm{CO}$ level of 4 to $6 \mathrm{ppm}$ were categorized as light smokers and $\geq 7 \mathrm{ppm}$ as regular smokers [2].

\section{Procedures}

Identified participants were screened using exhaled $\mathrm{CO}$ to identify their smoking status in addition to self-report for any tobacco use. The participants answered the self-administered questionnaire for approximately $25-30 \mathrm{~min}$. To ensure confidentiality, the participants were informed that there will be no identifiers recorded, only group data will be analyzed and the results will not be disclosed to their parents, teachers or peers. Based on the questionnaire responses, the participants were categorized into sole $\mathrm{CC}$, sole EC, or dual (CC and EC) user categories. 


\section{Statistical analysis}

Descriptive and categorical variables were summarized as frequencies and percentages. Chi-square test was used to assess the relationship between sociodemographic, socioeconomic and adolescent smoking status. A multivariate multinomial logistic regression was employed to model the relationship between the predictors and the three smoking statuses (sole CC, sole EC, and dual tobacco users), with dual users as the reference. Household monthly income (with MYR $>4000$ as the reference group), HONC ( $\geq 1$ as reference), $\mathrm{CO}$ ( $\geq 7 \mathrm{ppm}$ as reference), daily pocket allowance (MYR $\geq 10$ as reference), gender (female as reference), ethnicity (non-Bumiputera as reference), part-time working status (not working part-time as reference), and age (17 years old as reference) were entered as predictors. All analyses were performed using IBM SPSS v.20 (Chicago, IL: SPSS Inc.) software.

\section{Results}

Demographics, socioeconomic characteristics and

\section{smoking status}

Of the 422 adolescents $(M$ age $=15.58, S D=1.24), 90.3 \%$ were males and $69.4 \%$ were from the upper form (Form 3 onwards $/>15$ years old). The majority were of Malay ethnicity $(88.6 \%)$ and from the monthly household income group of between MYR1,001-4000 per month $(82.2 \%)$. More than half of the participants initiated smoking between 13 to 17 years old (59.0\%). Most adolescents $(89.3 \%)$ had a daily pocket allowance of less than MYR10 per day and 12\% reported working part-time. More than half reported that they were single users, with a total of 308 (73.0\%) participants reporting EC use. The mean CO reading was $2.14 \mathrm{ppm}$ with $78.0 \%$ of adolescents scoring more than 0 on the HONC. The response rate of the study was $100 \%$ because there were no refusers (Table 1 ).

\section{Characteristics associated with smoking status}

Table 2 shows that smoking among adolescents was significantly associated with the upper form $(69.4 \%, p<0.001)$, age 15 years and above $(69.8 \%, p<0.001)$, Bumiputera ethnicity $(78.2 \%, p<0.001)$ and males $(90.4 \%, p<0.001)$. Smoking status was significantly associated with adolescents with monthly household income of less than RM4,000 (88.6\%, $p=0.03)$ and part-time workers $(12.1 \%, p=0.006)$ but was not significantly related to daily pocket allowance. Household income was also statistically related to smoking initiation age $(p=0.033)$. Adolescents with HONC reading of $\geq 1(78.5 \%, p<0.001)$ were also related with smoking status even though their $\mathrm{CO}$ level $<4$ ppm $(79.9 p<0.001)$.
Table 1 Demographic and socioeconomic characteristics of study participants $(N=422)$

\begin{tabular}{|c|c|}
\hline Characteristic & n (\%) \\
\hline \multicolumn{2}{|l|}{ Form } \\
\hline Form 1 & $35(8.4)$ \\
\hline Form 2 & $94(22.3)$ \\
\hline Form 3 & $90(21.3)$ \\
\hline Form 4 & $125(29.6)$ \\
\hline Form 5 & $78(18.4)$ \\
\hline \multicolumn{2}{|c|}{ Age (Years), $(M=15.3, S D=1.24)$} \\
\hline 13 & $34(8.1)$ \\
\hline 14 & $93(22.0)$ \\
\hline 15 & $90(21.3)$ \\
\hline 16 & $123(29.1)$ \\
\hline 17 & $82(19.4)$ \\
\hline \multicolumn{2}{|c|}{ Initiation age of smoking (Years) } \\
\hline$<7$ & $5(1.2)$ \\
\hline $7-12$ & $168(39.8)$ \\
\hline $13-17$ & $249(59.0)$ \\
\hline \multicolumn{2}{|l|}{ Gender } \\
\hline Male & $381(90.3)$ \\
\hline Female & $41(9.7)$ \\
\hline \multicolumn{2}{|l|}{ Ethnicity } \\
\hline Bumiputera & $331(78.4)$ \\
\hline Non-Bumiputera & $91(21.6)$ \\
\hline \multicolumn{2}{|c|}{ Daily Pocket Allowance (MYR) } \\
\hline$<2$ & $21(5.0)$ \\
\hline $2-<5$ & $180(42.7)$ \\
\hline $5-<10$ & $176(41.7)$ \\
\hline$\geq 10$ & $45(10.7)$ \\
\hline \multicolumn{2}{|c|}{ Household Monthly Family Income (MYR) } \\
\hline$\leq 1000$ & $27(6.4)$ \\
\hline $1001-4000$ & $347(82.2)$ \\
\hline$\geq$ RM 4000 & $48(11.4)$ \\
\hline \multicolumn{2}{|c|}{ Working After School (Student) } \\
\hline Yes & $51(12.1)$ \\
\hline No & $371(87.9)$ \\
\hline \multicolumn{2}{|l|}{ Smoking Status } \\
\hline Sole CC & $114(27.0)$ \\
\hline Sole EC & $178(42.2)$ \\
\hline Dual user (CC and EC) & $130(30.8)$ \\
\hline \multicolumn{2}{|l|}{$\operatorname{HONC}(\mathrm{M}=2.65, \mathrm{SD}=2.307)$} \\
\hline Not Hooked $(<1)$ & $90(21.3)$ \\
\hline Hooked $(\geq 1)$ & $332(78.7)$ \\
\hline \multicolumn{2}{|c|}{ CO ppm ( $M=2.1, S D=2.682)$} \\
\hline Non-Smoker (1-3) & $337(79.9)$ \\
\hline Light Smoker (4-6) & $60(14.2)$ \\
\hline Regular Smoker ( $\geq 7)$ & $29(6.9)$ \\
\hline
\end{tabular}

CO carbon monoxide, ppm parts per million, SD standard deviation, HONC Hooked on Nicotine Checklist 
Table 2 The association between demographic and socioeconomic characteristics with smoking status $(N=422)$

\begin{tabular}{|c|c|c|c|c|}
\hline Characteristic & Sole CC $(n=114)$ & Sole EC $(n=178)$ & Dual Users (CC and EC) $(n=130)$ & Chi-Square $P$-value \\
\hline Form & & & & $<0.001$ \\
\hline Form 1 & 6 & 20 & 9 & \\
\hline Form 2 & 34 & 36 & 24 & \\
\hline Form 3 & 36 & 16 & 38 & \\
\hline Form 4 & 31 & 61 & 33 & \\
\hline Form 5 & 7 & 45 & 26 & \\
\hline Age & & & & $<0.001$ \\
\hline 13 & 6 & 19 & 9 & \\
\hline 14 & 34 & 35 & 24 & \\
\hline 15 & 36 & 18 & 36 & \\
\hline 16 & 31 & 58 & 34 & \\
\hline 17 & 7 & 48 & 27 & \\
\hline Gender & & & & $<0.001$ \\
\hline Male & 111 & 164 & 106 & \\
\hline Female & 3 & 14 & 24 & \\
\hline Ethnicity & & & & $<0.001$ \\
\hline Bumiputra & 106 & 115 & 110 & \\
\hline Non-bumiputra & 8 & 63 & 20 & \\
\hline Daily Pocket Allowance (MYR) & & & & 0.305 \\
\hline$<2$ & 10 & 6 & 2 & \\
\hline $2-<5$ & 52 & 78 & 38 & \\
\hline $5-<10$ & 42 & 74 & 42 & \\
\hline$\geq 10$ & 10 & 20 & 8 & \\
\hline Household Monthly Family Income (MYR) & & & & 0.005 \\
\hline 1000 and below & 15 & 5 & 7 & \\
\hline 1001-RM 4000 & 91 & 148 & 108 & \\
\hline 4000 and above & 8 & 25 & 15 & \\
\hline Part-time Worker & & & & 0.003 \\
\hline Yes & 22 & 11 & 18 & \\
\hline No & 92 & 167 & 112 & \\
\hline HONC & & & & $<0.001$ \\
\hline Not Hooked $(<1)$ & 10 & 67 & 13 & \\
\hline Hooked $(\geq 1)$ & 104 & 111 & 117 & \\
\hline CO ppm & & & & $<0.001$ \\
\hline Non-Smoker (1-3) & 75 & 164 & 98 & \\
\hline Light Smoker (4-6) & 28 & 11 & 21 & \\
\hline Regular Smoker $(\geq 7)$ & 11 & 3 & 11 & \\
\hline
\end{tabular}

CO carbon monoxide, ppm parts per million, SD standard deviation, HONC Hooked on Nicotine Checklist

However, results showed that adolescent smoking status was not significantly associated with daily pocket allowance and HONC level.

\section{Risk factors for sole CC and EC smoking}

Results from the multivariate multinomial logistic regression indicated that higher risks for being sole $\mathrm{CC}$ users were being male (OR 9.887, 95\% CI 2.737, 35.721), aged 15 years old (OR 3.844, 95\% CI 1.349, 10.949) and aged 16 years old (OR 3.385, 95\% CI 1.199, 9.551). Meanwhile, higher risks for being sole EC users were being male (OR 2.220, 95\% CI 1.005, 4.900), not being hooked on smoking (OR 3.951, 95\% CI 1.862, 8.387) and non-smoker status based on $\mathrm{CO}$ reading of $1-3 \mathrm{ppm}$ 
(OR 5.777, 95\% CI 1.407, 23.716). Meanwhile, Bumiputeras had a lower risk of sole EC smoking (OR 0.467, 95\% CI 0.219, 0.994) (Table 3).

\section{Discussion}

This study revealed that Malaysian adolescents in Kuala Lumpur who were male and aged 15 and 16 years were at increased risks of sole CC smoking. Meanwhile, males, those who are not hooked on smoking and with a non-smoker
$\mathrm{CO}$ reading were at increased risks of sole EC smoking. Finally, Bumiputeras were at less risk of EC smoking.

The findings showed being male increased the risk of smoking CC by nearly 10 folds while the risk of smoking EC was more than 2-fold compared to females. This is in line with previous studies from Malaysia [14, 17] and abroad [16], which found a higher prevalence of smoking in males compared to females. Asian males are also at a significantly greater risk of smoking than females, who were between 7 and 15 times less likely than males to

Table 3 Modelling the adjusted odds between CC or EC versus Dual User using multivariate multinomial logistic regression ( $N=422)$

\begin{tabular}{|c|c|c|}
\hline \multirow[t]{3}{*}{ Smoking Status } & Sole CC & Sole EC \\
\hline & OR & OR \\
\hline & $(95 \%$ Cl) & (Cl 95\%) \\
\hline \multicolumn{3}{|c|}{ Household Monthly Income (MYR) } \\
\hline 1000 and below & $5.154(0.407-65.216)$ & $0.464(0.025-8.598)$ \\
\hline $1001-4000$ & $2.034(0.297-13.933)$ & $1.840(0.409-8.272)$ \\
\hline 4000 and above ${ }^{a}$ & 1.000 & 1.000 \\
\hline \multicolumn{3}{|l|}{ HONC } \\
\hline Not Hooked $(<1)$ & $1.252(0.474-3.303)$ & $3.951(1.862-8.387) * * *$ \\
\hline Hooked $(\geq 1)^{a}$ & 1.000 & 1.000 \\
\hline \multicolumn{3}{|l|}{ CO (ppm) } \\
\hline Non-Smoker (1-3) & $0.689(0.254-1.872)$ & $5.777(1.407-23.716)$ \\
\hline Light Smoker (4-6) & $1.308(0.420-4.074)$ & $1.968(0.399-9.704)$ \\
\hline Regular Smoker $(\geq 7)^{a}$ & 1.000 & 1.000 \\
\hline \multicolumn{3}{|c|}{ Daily Pocket Allowance (MYR) } \\
\hline$<2$ & $0.465(0.030-7.140)$ & $2.930(0.140-61.196)$ \\
\hline $2-<5$ & $0.645(0.101-4.099)$ & $0.910(0.196-4.231)$ \\
\hline $5-<10$ & $0.423(0.068-2.629)$ & $0.955(0.215-4.232)$ \\
\hline$\geq 10^{a}$ & 1.000 & 1.000 \\
\hline \multicolumn{3}{|l|}{ Gender } \\
\hline Male & $9.887(2.737-35.721) * * *$ & $2.220(1.005-4.900) * *$ \\
\hline Female $^{\mathrm{a}}$ & 1.000 & 1.000 \\
\hline \multicolumn{3}{|l|}{ Ethnicity } \\
\hline Bumiputera & $1.542(0.554-4.293)$ & $0.467(0.219-0.994) * *$ \\
\hline Non-Bumiputera ${ }^{a}$ & 1.000 & 1.000 \\
\hline \multicolumn{3}{|l|}{ Part-time Worker } \\
\hline Yes & $1.561(0.723-3.374)$ & $0.428(0.179-1.021)$ \\
\hline No & 1.000 & 1.000 \\
\hline \multicolumn{3}{|l|}{ Age } \\
\hline 13 & 3.049 (0.848-10.968) & $1.107(0-0)$ \\
\hline 14 & $3.56(3.56-3.56)$ & $7.368(0-0)$ \\
\hline 15 & $3.844(1.349-10.949) * *$ & $0.384(0.159-0.930)$ \\
\hline 16 & $3.385(1.199-9.551)^{* *}$ & $1.542(0.721-3.299)$ \\
\hline 17 & 1.000 & 1.000 \\
\hline
\end{tabular}

Reference group: Dual user which includes CC and EC

$*^{* *} p<0.001$. ${ }^{* *} p<0.01$

${ }^{\text {a }}$ Reference Group 
report any smoking behavior [18]. This may be explained by the prevalent culture which is more accepting of male smokers compared female smokers [19]. However, the risk of smoking EC is lower compared to the risk of smoking $\mathrm{CC}$ for males. This is perhaps the $\mathrm{EC}$ smoking trend is less stigmatized compared to smoking $\mathrm{CC}$ among females. In addition, smoking EC is perceived as a trendy behavior and is more acceptable among adolescents [6]. EC offers a variety of flavours (vanilla, chocolate) which could attract more females and adolescents to try and become hooked.

The risk of 15- and 16-year-old adolescents reporting being sole CC users was higher compared to 17-year-olds, which was not consistent with findings from previous studies $[14,15,21]$, where older adolescents were at a higher risk of smoking compared to those who were younger. This might be related to the Sijil Pelajaran Malaysia public examination (equivalent to O-Levels), which may motivate 17-year-olds to be more concerned about their studies. In addition, these older adolescents may have a higher awareness of the health consequences of smoking as they approach their examination.

An interesting finding is that Bumiputera adolescents are at a lower risk of smoking EC. This might be related to their lower SES which did not allow them to buy and maintain EC use. In this study a majority of respondents belonged to the family income of $<$ MYR 4000 and EC is related to usage among those with higher SES [22]. This is also in line with previous Malaysian studies which indicated CC smoking is preferred among Bumiputeras based on its price and accessibility $[17,23]$. In comparison, Chinese adolescents reported being discouraged from smoking $\mathrm{CC}$ and perceived smoking $\mathrm{CC}$ as an unhealthy behavior due to receiving similar health-related messages from their elders [24], therefore may choose EC as their smoking preference.

The findings showed that adolescent smoking status was not predicted by household income, working parttime and daily allowance. This is inconsistent with past studies where socioeconomic status and personal income were significant predictors of smoking risk [27-31]. This may be due to the low rate of adolescents who report working part-time $(12 \%)$, as they may be reluctant to report having a job, as working is prohibited by the law for those under 18 years in Malaysia. In addition, SES may be a weaker predictor of smoking status compared to gender and age. This is because even though Malaysia is one of the countries that implement cigarette taxes, the price of cigarettes in Malaysia is relatively lower [15] due to the the rampant sale of illicit cigarettes [10]. Therefore, the affordability of cigarettes may only minimally affect smoking behavior among adolescents from the lower SES group.

EC appears to be a popular smoking preference among adolescents, with $73 \%$ of them reporting EC use in this study. The regulation of EC varies across countries. Presently, in Malaysia, ECs are not banned but are regulated with only nicotine-free e-liquids permitted to be sold by vendors [6]. However, the products are widely available and accessible to youth [17]. There is no barrier to purchasing EC and they are openly available in online stores, roadside stalls/night markets at a low price [10]. This situation contradicts the WHO Framework Convention on Tobacco Control (FCTC), of which Malaysia is a member since September 2005 [17]. There is also the perception that smoking CC poses higher health risks compared to smoking EC. However, extant literature revealed that smoking EC exposed smokers to residual risks due to a lack of control in quality and standards [35]. Therefore, health promotion programs need to address the gap of knowledge in public regarding the relative risks of smoking CC and EC.

Interestingly, the finding reveals that adolescents were also more likely to report using tobacco products even though they were categorized as non-smokers based on their $\mathrm{CO}$ level of $<4 \mathrm{ppm}$. This could be due to the failure to capture smoking status through exhaled $\mathrm{CO}$ in spite of self-reported smoking status by the adolescents. Nevertheless, the validity of self-reported smoking has been indicated in a Jordan study, where adolescents tended to be truthful when confidentiality is assured [36]. In addition, adolescents who were very light smokers usually smoke fewer than 6 cigarettes per day [37] and tended to buy single loose cigarettes [38]. The light smokers normally have a lower reading of exhaled carbon monoxide. Furthermore, they may have smoked the last cigarette more than $8 \mathrm{~h}$ prior to the breath test at school, hence CO level may have returned to normal. Since $49 \%$ of adolescents were sole EC users, this also contributes to the low expired CO concentration observed [39].

\section{Limitations and strengths}

To our best knowledge, this the first study in this region to examine the relationship between demographics, socioeconomic status and adolescent smoking status within multiple groups of tobacco types such as sole EC, sole CC, dual users. However, it has a few limitations. This study was conducted in the Federal Territory of Kuala Lumpur and therefore may not be generalizable to other states in Malaysia. The authors were not able to validate EC use due to financial constraints and therefore depended on the self-report of the participants, unlike CC use which was validated using $\mathrm{CO}$ reading. This may lead to inconsistency in the smoking status.

\section{Conclusions}

Adolescents' smoking status was found to be associated with age, gender, ethnicity, exhaled CO level and being hooked to smoking. These findings are important as they single out those who are most at risk of smoking, and this information provides an indication for targeting specific demographic groups in smoking cessation programs for adolescents. 


\section{Abbreviations}

B40: Bottom 40\%; CC: Conventional cigarette; CO: Carbon monoxide; DU: Dual users; EC: Electronic cigarette; Malaysia; HONC: Hooked-on Nicotine Checklist; M40: Middle 40\%; MMLR: Multivariate multinomial logistic regression; PPM: Parts Per Million; SD: Standard Deviation; SES: Socioeconomic Status; SPSS: Statistical Package for Social Sciences; T20: Top 20\%; TECMA: Tobacco \& E-Cigarette Survey among Malaysian Adolescents; WHO FCTC: WHO Framework Convention on Tobacco Control

\section{Acknowledgements}

We sincerely thank our participants and the school management for assisting in this study. We would also like to thank Ms. Lena Yeap Lay Ling (Stats Consulting Pte. Ltd.) and Dr. S. N. Yogarabindranath (Ministry of Health Malaysia) for statistical advice.

\section{Funding}

This study was funded by Geran Universiti Penyelidikan (GUP-2017-058), the National University of Malaysia. The authors also acknowledged the financial assistance for publication received from the Research University Grant awarded by the Ministry of Health to the National University of Malaysia specifically for the Consortium of B40 Research (CB40R) under the auspice of B40 Grand Challenges (IDE 2018-01).

\section{Availability of data and materials}

The datasets generated and analyzed during the current study are available from the corresponding author upon reasonable request.

\section{About this supplement}

This article has been published as part of BMC Public Health Volume 19 Supplement 4, 2019: Health and Nutritional Issues Among Low Income Population in Malaysia. The full contents of the supplement are available online at https://bmcpublichealth.biomedcentral.com/articles/supplements/ volume-19-supplement-4.

\section{Authors' contributions}

WLH and NAAH conceived the study. NAAH and SJJS collected the data. NAAH and NZMS conducted the statistical analysis. NAAH, WLH and SCS wrote the first draft of the manuscript. All authors contributed significantly to the writing and editing of the final manuscript. All of the authors have also read and approved the manuscript.

\section{Ethics approval and consent to participate}

The study questionnaire, protocols, consent forms, participant information sheet and study-related flyer to recruit the study subjects were approved by the Research Ethics Committee, The National University of Malaysia (JEP2017-794). This study also obtained approval from the Education Department of the Federal Territory, Ministry of Education, and school management. Written consent was obtained from all the participants (adolescent assent) and the parents/guardian (parental consent) before their enrolment in the study.

\section{Consent for publication}

Not applicable, there are no personal details on individuals reported within the manuscript.

\section{Competing interests}

The authors declare that they have no competing interests.

\section{Publisher's Note}

Springer Nature remains neutral with regard to jurisdictional claims in published maps and institutional affiliations.

\section{Author details}

${ }^{1}$ Health Education Program, Community Health Centre, Faculty of Health Sciences, The National University of Malaysia (UKM), Kuala Lumpur, Malaysia. ${ }^{2}$ Kulliyah of Pharmacy, International Islamic of Malaysia (UIA), Kuala Lumpur, Malaysia. ${ }^{3}$ National Cancer Society Malaysia (NCSM), Kuala Lumpur, Malaysia ${ }^{4}$ Faculty of Social Sciences and Liberal Arts, UCSI University, Kuala Lumpur, Malaysia.

\section{Published: 13 June 2019}

\section{References}

1. Green MJ, Stritzel H, Smith C, Popham F, Crosnoe R. Timing of poverty in childhood and adolescent health: evidence from the US and UK. Soc Sci Med. 2018;197:136-43.

2. Sargent JD, Gabrielli J, Budney A, Soneji S, Wills TA. Adolescent smoking experimentation as a predictor of daily cigarette smoking. Drug Alcohol Depend. 2017:175:55-9.

3. White J, Li J, Newcombe R, Walton D. Tripling use of electronic cigarettes among New Zealand adolescents between 2012 and 2014. J Adolesc Health. 2015;56:522-8

4. Wee LH. A review of smoking research in Malaysia. Med J Malays. 2016:71:29.

5. Al-Naggar RA, Bobryshev YV, Anil S. Pattern of shisha and cigarette smoking in the general population in Malaysia. Asian Pac J Cancer Prev. 2014;15: 10841-6.

6. Mohamed MH, Rahman A, Jamshed S, Mahmood S. Effectiveness and safety of electronic cigarettes among sole and dual user vapers in Kuantan and Pekan, Malaysia: a six-month observational study. BMC Pub Health. 2018;18:1028.

7. Jawad M, Cheeseman H, Brose LS. Waterpipe tobacco smoking prevalence among young people in Great Britain, 2013-2016. Eur J Pub Health. 2017;28: 548-52.

8. Lechner WW, Murphy CM, Colby SM, Janssen T, Rogers ML, Jackson KM. Cognitive risk factors of electronic and combustible cigarette use in adolescents. Addict Behav. 2018;82:182-8.

9. Ramachandra SS, Yaldrum A. Shisha smoking. An emerging trend in southeast Asian nations. J Public Health Policy. 2015;36:304-17.

10. Ministry of Health Malaysia. Tobacco and E-Cigarette Report 2016. Putrajaya: Ministry of Health Malaysia; 2016. Available from: iku.moh.gov.my/index.php/ research-eng/list-of-research-eng/iku.../tecma-2016. Accessed 30 Sept 2018.

11. Owotomo O, Maslowsky J, Loukas A. Perceptions of the harm and addictiveness of conventional cigarette smoking among adolescent Ecigarette users. J Adolesc Health. 2018;62:87-93.

12. Wong LP, Alias H, Aghamohammadi N, Aghazadeh S, Hoe VC. Shisha smoking practices, use reasons, attitudes, health effects and intentions to quit among shisha smokers in Malaysia. Int J Environ Res Public Health. 2016:13:726

13. Haardörfer R, Berg CJ, Lewis M, Payne J, Pillai D, McDonald B, et al. Polytobacco, marijuana, and alcohol use patterns in college students: a latent class analysis. Addict Behav. 2016;59:58-64.

14. Lim KH, Lim HL, Teh CH, Kee CC, Khoo YY, Ganapathy SS, et al. Smoking among school-going adolescents in selected secondary schools in peninsular Malaysia-findings from the Malaysian adolescent health risk behaviour (MyaHRB) study. Tob Induc Dis. 2017:15:1-8.

15. Tohid H, Ishak NM, Muhammad NA, Hassan HA, Ahmad FNM, Omar K. What determines teenagers' smoking behavior?: a qualitative study. Int Med J. 2011;18:194-8

16. Backhaus I, D'Egidio V, Grassucci D, Gelardini M, Ardizzone C, La Torre G. Link between perceived smoking behavior at school and students smoking status: a large survey among Italian adolescents. Pub Health. 2017;151:169-76.

17. Afiah N, Azhar S. Smoking behavior among adolescents in rural schools in Malacca, Malaysia: a case-control study. Pertanika J Sci Technol. 2015;23:13-28.

18. European Commission. Health statistics-key data on health 2002-data 19702001. Available from: https://ec.europa.eu/eurostat/documents/3217494/ 5655953/KS-08-02-002-EN.PDF/46ba8386-07eb-4661-9827-322995aac43d. Accessed 30 Sept 2018.

19. Kalaboka S, Piau JP, King G, Moreau D, Choquet M, Annesi-Maesano I. Sex and gender differences in tobacco smoking among adolescents in French secondary schools. Monaldi Arch Chest Dis. 2016:69:142-51.

20. Fix BV, O'Connor RJ, Vogl L, Smith D, Bansal-Travers M, Conway KP, et al. Patterns and correlates of polytobacco use in the United States over a decade: NSDUH 2002-2011. Addict Behav. 2014;39:768-81.

21. Reidpath DD, Davey TM, Kadirvelu A, Soyiri IN, Allotey P. Does one cigarette make an adolescent smoker, and is it influenced by age and age of smoking initiation? Evidence of association from the US youth risk behavior surveillance system (2011). Prev Med. 2014:59:37-41.

22. Simon P, Camenga DR, Morean ME, Kong G, Bold KW, Cavallo DA, et al. Socioeconomic status and adolescent e-cigarette use: the mediating role of e-cigarette advertisement exposure. Prev Med. 2018;112:193-8.

23. Khairani $O$, Norazua $R$, Zaiton A. Prevalence and reasons for smoking among upper secondary schoolboys in Hulu Langat, Malaysia. Med Health. 2007;2:80-5. 
24. Dahlui M, Jahan NK, Majid HA, Jalaludin MY, Murray L, Cantwell M, et al. Risk and protective factors for cigarette use in young adolescents in a school setting: what could be done better? PLoS One. 2015;10:e0129628.

25. Huisman M, Kunst AE, Mackenbach JP. Inequalities in the prevalence of smoking in the European Union: comparing education and income. Prev Med. 2005:40:756-64.

26. Kuntz B, Lampert T. Smoking and passive smoke exposure among adolescents in Germany: prevalence, trends over time, and differences between social groups. Dtsch Arztebl Int. 2016;113:23.

27. Moor I, Rathmann K, Lenzi M, Pförtner TK, Nagelhout GE, de Looze M, et al. Socioeconomic inequalities in adolescent smoking across 35 countries: a multilevel analysis of the role of family, school and peers. Eur J Pub Health. 2015;25:457-63.

28. Lund M. Social inequality in cigarette consumption, cigarette dependence, and intention to quit among Norwegian smokers. Biomed Res Int. 2015;2015:1-7.

29. Gagné T, Frohlich KL, Abel T. Cultural capital and smoking in young adults: applying new indicators to explore social inequalities in health behavior. Eur J Pub Health. 2015;25:818-23.

30. Schori D, Hofmann K, Abel T. Social inequality and smoking in young Swiss men: intergenerational transmission of cultural capital and health orientation. Int J Environ Res Public Health. 2014;59:261-70.

31. West $P$, Sweeting H, Young R. Smoking in Scottish youths: personal income, parental social class and the cost of smoking. Tob Control. 2007;16:329-35.

32. Ambrose BK, Rostron BL, Johnson SE, Portnoy DB, Apelberg BJ, Kaufman AR, et al. Perceptions of the relative harm of cigarettes and e-cigarettes among US youth. Am J Prev Med. 2014:47:53-60.

33. Wheeler KC, Fletcher KE, Wellman RJ, Difranza JR. Screening adolescents for nicotine dependence: the hooked on nicotine checklist. J Adolesc Health. 2004;35:225-30

34. Alberta Health Services. Tobacco Cessation Toolkit Hooked on Nicotine Checklist (HONC). Available from: https://www.albertaquits.ca/files/AB/files/ library/HONC.pdf. Accessed 30 Sept 2018.

35. Farsalinos KE, Polosa R. Safety evaluation and risk assessment of electronic cigarettes as tobacco cigarette substitutes: a systematic review. Ther Adv Drug Saf. 2014;5:67-86.

36. Al-Sheyab N, Kheirallah KA, Mangnall LJ, Gallagher R. Agreement between exhaled breath carbon monoxide threshold levels and self-reported cigarette smoking in a sample of male adolescents in Jordan. Int J Environ Res Pub Health. 2015;12:841-54.

37. Pinsker EA, Hennrikus DJ, Hannan PJ, Lando HA, Brosseau LM. Smoking patterns, quit behaviors, and smoking environment of workers in small manufacturing companies. Am J Ind Med. 2015;58:996-1007.

38. Syamlal G, Mazurek JM, Hendricks SA, Jamal A. Cigarette smoking trends among US working adult by industry and occupation: findings from the 20042012 National Health Interview Survey. Nicotine Tob Res. 2014;17:599-606.

39. Hawkins SS, Bach N, Baum CF. Impact of tobacco control policies on adolescent smoking. J Adolesc Health. 2016;58:679-85.

Ready to submit your research? Choose BMC and benefit from:

- fast, convenient online submission

- thorough peer review by experienced researchers in your field

- rapid publication on acceptance

- support for research data, including large and complex data types

- gold Open Access which fosters wider collaboration and increased citations

- maximum visibility for your research: over $100 \mathrm{M}$ website views per year

At BMC, research is always in progress.

Learn more biomedcentral.com/submissions 